Revista Perspectivas Online: Humanas \& Sociais Aplicadas

Abril de 2018, Vol.8, n 21, p. 37-50

ISSN: 2236-8876 (Online)

DOI: $10.25242 / 887682120181288$

\title{
TRABALHO NOTURNO: SEUS EFEITOS NA SAÚDE DOS TRABALHADORES DA ÁREA DE SAÚDE
}

\author{
Wesley Rodrigues da Costa', Raquel Pereira Belo², Mayara dos Santos Sales ${ }^{3}$, Igor de Castro \\ Sales $^{3}$ \& Pollyana Nathércia de Vasconcelos Rodrigues ${ }^{3}$
}

\section{RESUMO}

COSTA, W. R.; BELO, R. P.; SALES, M. S.; SALES, I. C.; RODRIGUES, P. N. V. Trabalho noturno: seus efeitos na saúde dos trabalhadores da área de saúde. Perspectivas Online: Humanas \& Sociais Aplicadas, v. 8, n.21, p.37-50, 2018.

A presente pesquisa situa-se no âmbito da análise psicossocial do trabalho e das organizações e teve por objetivo conhecer os efeitos do trabalho noturno na saúde dos trabalhadores que atuam no ramo da saúde na cidade de Parnaíba-PI. A pesquisa foi realizada com 25 profissionais, todos os participantes tinham idade acima de 18 anos. O instrumento foi um roteiro de entrevista semi estruturada e um questionário sociodemográfico a fim de que se conhecesse o perfil dos participantes. A análise dos dados foi feita por meio do software IRAMUTEQ. A partir da análise dos dados foi possível perceber aspectos significativos do cotidiano laboral desses profissionais que influem na sua saúde, tais como alteração no sono, no lazer e nas relações sociais comprometidas pela falta de tempo em decorrência dos vínculos empregatícios. Tais resultados corroboram com achados de outras pesquisas já realizadas que pontuam algumas consequências das alterações no ritmo biológico em decorrência do trabalho noturno, quais sejam, por exemplo, a baixa capacidade de conciliar o sono normal e a fadiga. Nesta dinâmica, os profissionais priorizam as atividades domésticas, em alguns casos existe insatisfação com o horário de trabalho e perspectivas de mudança para o expediente diurno.

Palavras-Chave: Saúde do trabalhador; Trabalho Noturno; Profissionais da Saúde. 


\begin{abstract}
This research is situated on the psychosocial analysis of work and organizations and aimed to know the effects of night work on the health of workers working in the health sector in the city of Parnaíba- PI. The research was carried out with 25 professionals, all participants were over 18 years of age. The instrument was a semistructured interview script and a sociodemographic questionnaire in order to know the profile of the participants. Data analysis was performed using IRAMUTEQ software. The results pointed out significant aspects of the daily

sleep, leisure and social relationships compromised by the lack of time due to employment links. These results corroborate with findings from other studies which have already been carried out that point to some consequences of changes in the biological rhythm as a result of night work, such as the low ability to reconcile normal sleep and fatigue. In this dynamic, professionals prioritize domestic activities, in some cases there is dissatisfaction about working hours and prospects of a change for the daytime expedient.
\end{abstract} life of these professionals, such as alteration in

Keywords: Worker's health; Night work; Health professionals.

${ }^{1}$ Psicólogo pela Universidade Federal do Piauí; membro do Grupo de Pesquisa em Análise Psicossocial do Trabalho e das Organizações

${ }^{2}$ Professora adjunto 4 da Universidade Federal do Piauí, Coordenadora do Grupo de Pesquisa em Análise Psicossocial do Trabalho e das Organizações;

${ }^{3}$ Discentes do curso de Psicologia pela Universidade Federal do Piauí, membros do Grupo de Pesquisa em Análise Psicossocial do Trabalho e das Organizações;

(*)e-mail: wesleyrodrigo.p@icloud.com

Data de chegada: 17/12/2017 Aceito para publicação: 12/05/2018

Persp. online: hum. \& sociais aplicada., Campos dos Goytacazes, 21 (8), 37-50, 2018

seer.perspectivasonline.com.br 


\section{INTRODUÇÃO}

As transformações no mundo trabalhista têm acontecido ao longo dos anos desde o período da era primitiva. No principio, as pessoas se utilizavam do trabalho apenas com a finalidade de subsistência. Com o passar do tempo, as técnicas trabalhistas foram evoluindo ano após ano, contando-se com as contribuições dos Gregos e Romanos, com o advento a Idade Média, com o Renascimento e com a Revolução Industrial, que exerceu papel fundamental no desenvolvimento do sistema de trabalho atual. Desta forma percebe-se uma mudança no cenário valorativo do trabalho, que passou a ser o mediador entre a mão de obra operária e o capital (ALBORNOZ, 2008). Com o advento das evoluções culturais e sociais, o trabalho foi atravessado também por eixos de cunho existencial, pois representa algo a mais que apenas fonte de riqueza, estando na condição básica e fundamental da vida dos seres humanos. A necessidade de aumento da lucratividade e a busca por parte do consumidor de conforto material proporcionaram o surgimento da Sociedade 24 horas, na qual as atividades laborais realizam-se em turnos, de forma a ocupar todas as horas do dia (SILVA, et al., 2010).

Atualmente é visível que a inserção das pessoas em postos de trabalho acontece também em horários noturnos, pois as necessidades criadas no desenvolvimento econômico do capital faz com que a sociedade funcione 24 horas por dia. Devido às constantes mudanças ocorridas no mundo no que tange à globalização e à evolução das tecnologias, observam-se melhorias consideráveis no modo como empresas podem tornar-se altamente competitivas e obter ganhos notórios de produtividade (RÉGIS FILHO, 2002), contudo, como afirma Neves et al. (2010) o fato dos trabalhadores desempenharem seu serviço no turno noturno de trabalho pode se tornar um fator negativo para a sua qualidade de vida, pois passam a ter um ritmo de vida diferente daquele conduzido por seus familiares e amigos. Os trabalhadores do serviço noturno têm um desgaste psicofisiológico maior do que aqueles que trabalham durante o dia, pois trabalham no momento em que as funções orgânicas encontram-se diminuídas. Os principais efeitos do trabalho noturno, partindo dos estudos já publicados, apontam para os prejuizos das horas de sono não dormidas acarretando problemas biológicos e psicológicos (CAMPOS; BELO, 2014). Desta forma, como consequência destas vivências pode-se pensar em comprometimento da saúde mental do profissional, na medida em que a saúde é considerada como um estado completo de bem-estar tanto em aspectos físicos como mental e social (OMS, 1948). Os conceitos acerca desta temática podem variar conforme a cultura, levando em consideração a noção de ser determinante da saúde geral (CAMARGO; NEVES, 2004).

Diante do exposto, a presente pesquisa teve por objetivo conhecer os efeitos do trabalho noturno na saúde dos trabalhadores que atuam no ramo da saúde. Trata-se de um estudo exploratório de natureza descritiva, o qual de acordo com Gil $(2008)$ objetiva que os resultados elucidem uma visão geral, de tipo aproximativo acerca do fato em questão, bem como fazer uma descrição das características da população estudada, configurando-se, portanto, como uma pesquisa social de cunho qualitativo. A motivação para o estudo partiu dos resultados obtidos por pesquisas já realizadas em Parnaíba (CAMPOS; BELO, 2014).

A pesquisa foi realizada com 25 profissionais da cidade, todos com idades acima de 18 anos. $\mathrm{O}$ instrumento foi um roteiro de entrevista semi estruturada e um questionário sociodemográfico a fim de que se conhecesse o perfil dos participantes. A análise dos dados foi feita utilizando-se de um software gratuito IRAMUTEQ, ancorado no software $\mathrm{R}$, de forma a permitir a análise estatística sobre corpus textuais, em diferentes tipos de análise como nuvem de palavras, estatísticas textuais clássicas, classificação hierárquica descendente, pesquisa de especificidades de grupos e análise de similitude. O IRAMUTEQ foi desenvolvido por Pierre Ratinaud inicialmente em língua francesa, começou a ser utilizado no Brasil no ano de 2013. Com esse software é possível realizar diferentes tipos de análise de dados textuais, que podem ser feitas por meio de corpus, que corresponde a um grupo de textos que tratam de uma determinada temática, reunidos em um único documento de texto (CAMARGO; JUSTO, 2013a). Os resultados apontaram aspectos significativos do cotidiano laboral desses profissionais, tais como alteração no sono, no lazer e nas relações sociais comprometidas pela falta de tempo em decorrência dos vínculos empregatícios. Nesta dinâmica, os profissionais priorizam as atividades domésticas, em alguns casos existe insatisfação com o horário de trabalho e perspectivas de mudança para o expediente diurno. Diante deste contexto percebe-se a relevância de realizar estudos acerca desta temática o que a justifica, tendo em vista a necessidade de não apenas conhecer e compreender os efeitos do trabalho em turno noturno na saúde dos trabalhadores, mas também

Persp. online: hum. \& sociais aplicada., Campos dos Goytacazes, 21 (8), 37-50, 2018

seer.perspectivasonline.com.br 
elaborar propostas interventivas que priorizem o bem-estar da categoria laboral atuante nestes contextos de trabalho.

\section{REFERENCIAL TEÓRICO}

\subsection{Considerações sobre o trabalho noturno}

Percebe-se que o oferecimento de serviços em horários diferentes do horário comercial vem aumentado nos últimos anos. São exemplos, os serviços de telecomunicações, processamentos bancários, distribuição de correspondência rápida, centros de compras como shoppings Centers e supermercados, hotéis, serviços de lazer, serviços educacionais, além dos serviços essenciais à vida do cidadão. Há, portanto, com o aumento do tempo de funcionamento desses locais, uma quantidade cada vez maior de produção de bens e prestação de serviços que funcionam de forma contínua, ou seja, 24 horas por dia (MORENO; FISHER; ROTENBERG, 2003).

Em virtude do que fora apresentado acerca do crescimento das ofertas de serviços para além do horário comercial, cabe citar o artigo 73 da Consolidação das Leis de Trabalho - CLT, que aborda aspectos relevantes quanto à definição de trabalho noturno como sendo aquele executado entre as 22 horas de um dia e as 5 horas do dia seguinte. Para as atividades rurais, considera-se trabalho noturno, aquele executado entre as 21 horas de um dia e às 5 horas do dia seguinte (BRASIL, 1943).

Nesta dinâmica chama atenção os aspectos relativos ao sono, que é definido como um estado comportamental de caráter fundamental na vida de uma pessoa (SANTOS; COSTA, 2016). Têm-se em vista dois processos fundamentais e determinantes no processo sono-vigília: o ritmo circadiano e o controle homeostático. O ritmo circadiano se repete a cada vinte e quatro horas, de forma que o organismo percebe as horas que são mais ou menos favoráveis ao sono. Ele rege o ciclo sono-vigília, e está relacionado a duração do período de luz conhecido como fotoperiodismo decorrente da alternância entre o período diurno e noturno e está sob o controle do núcleo supraquiasmático do hipotálamo (GOMES; QUINHONES; ENGELBARDT, 2010). Os sinais externos como, a luz e temperatura ambiente e os internos, como a fadiga e a sonolência também influenciam na percepção do organismo para o sono. O trabalho noturno e o estresse que envolvem o exercício da atividade laboral resultam na dessincronização do ritmo circadiano e nas alterações da vida social e familiar. Deve-se considerar ainda os impactos negativos no desempenho humano em relação ao estado de alerta e ao bem-estar em face da perturbação do ritmo circadiano e consequentemente a redução no tempo de repouso (BERTOLAZI, 2008; LISBOA, et al., 2010).

Segundo Codo, Sorato e Vasques-Menezes (2004) Saúde Mental configura-se como a capacidade de construir, produzir e reproduzir a si próprio e a espécie. Já a organização Mundial de Saúde considera a Saúde Mental um estado completo de bem-estar no aspecto físico, mental e social e não somente a ausência de doença ou enfermidade (OMS, 1948).

O campo da Saúde Mental inserido no contexto de trabalho foi dividido de forma didática em três grandes áreas, para que se fizesse possível uma análise do mesmo. Essas áreas compreendem a relação homem-natureza; a relação homem-sociedade; a relação homem consigo mesmo. A relação homem-natureza se dá em face das possibilidades e formas como a pessoa controla seu ambiente e/ou é controlada por ele, assim como o sentido que o trabalho adquire para o individuo e para a sociedade. A relação homemsociedade considera que o trabalho não se dá de forma desvinculada de uma sociedade, de forma que a divisão do trabalho e a hierarquia organizam os cotidianos das pessoas. A relação homem consigo mesmo considera a atitude do trabalhador frente ao trabalho, assim como a carga mental exigida em decorrência do exercício das atividades laborais como, os fatores tempo e tarefa em si (CODO, 2002).

Observa-se em pesquisas realizadas nos últimos anos que o trabalho no turno da noite influencia alguns aspectos da vida dos profissionais: considera-se diante dessa afirmação as implicações de ordem fisiológica e psicológica, as influências na vida laboral pelas implicações na qualidade de vida (JESUS, 2016b) e na vida familiar e social (SILVA; PRATA; FERREIRA, 2014). 
Assim, um dos fatores que chama atenção é a alteração do ciclo vigília-sono, visto que os profissionais em determinados dias estarão trabalhando e em outros dias terão folga. O sono humano é monofásico e está programado para ocorrer durante o período noturno, para que o ciclo sono-vigília seja organizado e controlado com precisão. A homeostase do sono pode ser pensada considerando a interação de dois processos: o primeiro é conhecido como processo $\mathrm{S}$ que aumenta durante a vigília e diminui durante o sono, e o segundo processo é impulsionado pelo relógio interno, de forma que o ritmo circadiano seja sensível aos fatores externos assumindo o papel de ajuda na manutenção do ciclo sono-vigília sincronizado com a alternância do dia-a-dia (DROUOT; QUENTIN, 2015).

Para Simplício et al. (2015) a qualidade de vida se correlaciona no processo saúde doença, no modo de viver e nas relações de trabalho. Os trabalhadores da saúde na área da enfermagem ao prestar assistência aos usuários do serviço ficam expostos à inúmeros riscos ocupacionais causados por fatores químicos, biológicos, mecânicos, físicos, ergonômicos, incluindo os psicossociais, factíveis de ocasionar doenças ocupacionais e acidentes de trabalho. Estas proposições podem ser verificadas também na revisão bibliográfica realizada por Jesus et al. (2016b) apontando efeitos negativos na saúde e qualidade de vida dos profissionais de enfermagem, motivado pelas condições de trabalho e pessoais.

Já fora mencionado neste documento que o exercício de atividade laboral no terceiro turno afeta a vida familiar e social dos profissionais. Assim, apresenta-se o estudo de revisão de literatura realizado por Jesus et al. (2016a) objetivando identificar os resultados das condições de trabalho noturno frente à saúde, vida social e familiar do profissional de enfermagem. Cabe uma atenção especial quanto aos resultados referentes aos aspectos da vida social e familiar visto que os resultados apontaram para a existência dos transtornos de forma a ocorrer pontos negativos para o trabalhador relacionados às condições trabalhistas. Considerando o que fora abordado, percebe-se a relevância da presente pesquisa cujo objetivo central consistiu em conhecer os efeitos do trabalho noturno na saúde dos trabalhadores que atuam no ramo da Saúde na cidade de Parnaíba-PI, buscando-se ainda verificar os principais impactos do trabalho noturno na saúde do trabalhador e realizar um levantamento dos principais efeitos na saúde dos trabalhadores da área da Saúde.

\section{METODOLOGIA}

O corpus textual foi composto por 25 entrevistas realizadas com os trabalhadores da categoria profissional da Saúde que trabalham em expediente noturno. Para participar da pesquisa, o profissional deveria ter expediente em regime de plantão de 12 ou 24 horas, e exercer sua profissão na área da Saúde. A amostra foi composta por conveniência, assim, os pesquisadores após solicitar anuência da administração da instituição, abordavam os servidores e perguntavam se poderiam responder a uma pesquisa. Após concordar, deveriam assinar o Termo de Consentimento Livre e Esclarecido para proceder com a entrevista que consistiu em uma questão disparadora.

$\mathrm{O}$ instrumento consistiu em um roteiro de entrevista semiestruturada e questionário sociodemográfico a fim de que se conhecesse o perfil dos participantes. As entrevistas realizaram-se em lugares públicos da cidade e/ou nos locais de trabalhos dos referidos profissionais. Independente da situação, durante a abordagem foi perguntado a cada pessoa se poderia participar de uma pesquisa realizada pelo curso de Graduação de Psicologia da Universidade Federal do Piauí, e, caso aceitasse, o respondente teria acesso a um Termo de Consentimento Livre e Esclarecido no qual ele poderia assinar se estivesse de acordo. O estudo seguiu as normas e procedimentos éticos conforme a Resolução 466/12 do Conselho Nacional de Saúde que estabelece as diretrizes e normas regulamentadoras de pesquisas envolvendo seres humanos.

A análise de dados se deu por meio do software IRAMUTEQ (Interface de $R$ pouranalysesMultidimensionnelles de Textes et de Questionneires, versão 0.7). Lahlou (2012) e Camargo \& Justo (2013) complementam-se ao apresentarem o IRAMUTEQ como um software originalmente francês, utilizado no Brasil desde 2013. Ancorado no software R (www.r-project.org), possibilita a realização de cálculos estatísticos distintos sobre corpus textuais e tabelas de indivíduos por intermédio da lexicografia, que diz respeito à frequência e estatística básica, além de algumas análises tais como nuvem de palavras, análise de similitude e classificação hierárquica descendente. 
A nuvem de palavras consiste em uma análise lexical mais simples e graficamente interessante por permitir uma breve identificação das palavras-chave que são elementares em um corpus textual. Esta análise agrupa as palavras e as organiza graficamente, conforme sua frequência.

Baseada na teoria dos grafos, a análise de similitude, como bem pontua Marchand \& Ratinaud (2012), é válida por permitir a identificação das co-ocorrências entre as palavras, seu resultado apresenta indicações da conexão entre os vocábulos, colaborando para a identificação da estrutura de um corpus textual.

Quanto à classificação hierárquica descendente (CHD), refere-se a uma análise que procura obter classes de segmento de texto que apresentem palavras que sejam semelhantes entre si, mas distintas das palavras de outras classes. Os segmentos do texto são classificados em função dos seus respectivos vocabulários, e o conjunto deste é repartido em função da frequência das formas reduzidas.

Acerca do material para análise, Camargo e Justo (2013) discorrem sobre um grupo de textos com mesma temática, sob a condição de estarem reunidos em um único arquivo de texto. Tal colocação diz respeito a tabelas com indivíduos em linhas e palavras em colunas, ou mesmo organizadas em planilhas, como bancos de dados estabelecidos a partir de testes de evocação livre.

\section{RESULTADOS}

As 25 entrevistas do corpus inicial foram analisadas, transformado-se em 282 segmentos de texto, com 5322 ocorrências, 1112 formas e 619 hapax (palavras que aparecem uma única vez no corpus), gerando uma média de 5322 ocorrências por texto.

Os seguimentos de texto foram submetidos à análise de Nuvem de Palavras, a fim de agrupar os vocábulos para uma visualização simples das palavras que surgiram com maior frequência no corpus. O resultado dessa análise pode ser visto na Figura 1 na qual é possível observar as palavras trabalhar, gente, noite, dia e plantão em destaque, indicando que estas aparecem com maior frequência no corpus. 


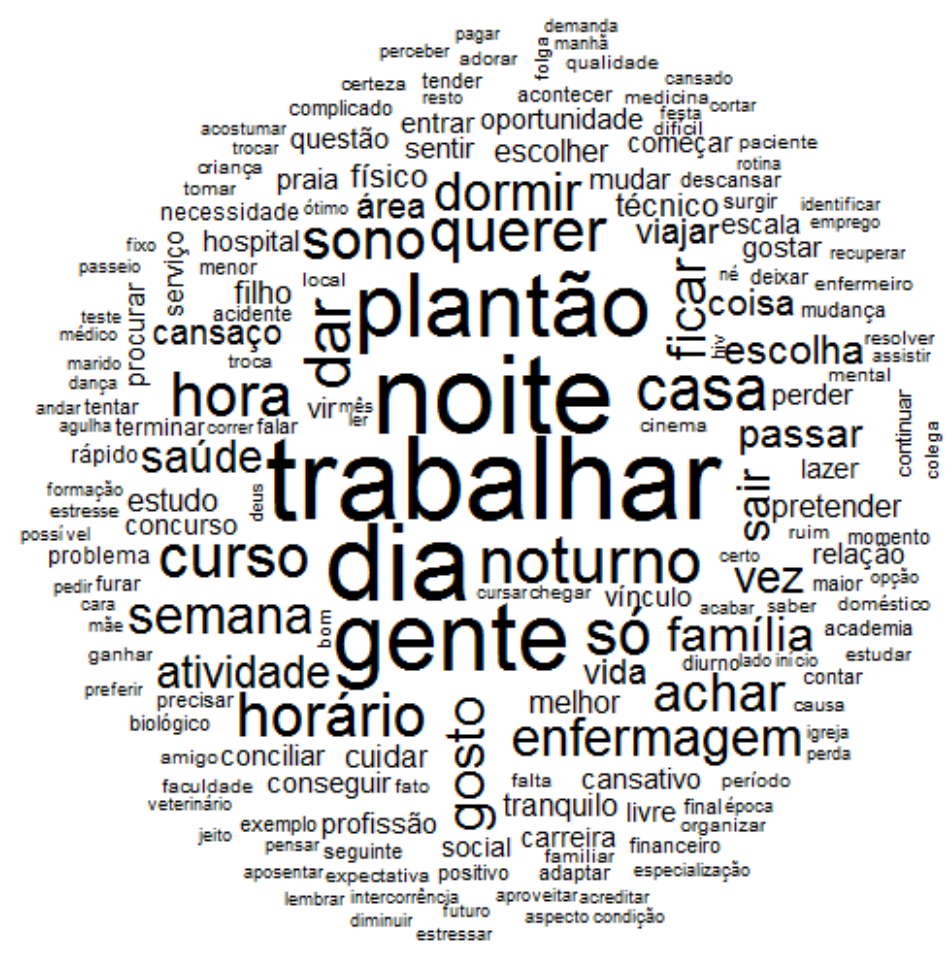

Figura 1. Nuvem de palavras para o Corpus Trabalho noturno na categoria profissional saúde

Quanto à análise da Classificação Hierárquica Descendente (CHD) foram considerados 218 segmentos de texto, com 812 de palavras lematizadas, 654 formas ativas, 15 formas suplementares, com média de 18,87 formas por segmento de texto, sendo considerando $77,30 \%$ dos segmentos de texto para a análise, satisfazendo critério mínimo apontado pela literatura $75 \%$ de aproveitamento do corpus (CAMARGO; JUSTO, 2016). Foram realizadas divisões sequenciais no Corpus até se originarem 6 Classes: a primeira divisão originou a Classe 6 e o segundo subcorpus; o segundo subcorpus originou a Classe 1 e o terceiro subcorpus; o terceiro subcorpus deu origem à Classe 5 e ao quarto subcorpus; o quarto subcorpus originou a Classe 2 e o quinto subcorpus; o quinto subcorpus dividiu-se nas Classes 3 e 4 . A divisão do corpus em seis classes pode ser observada na Figura 2.
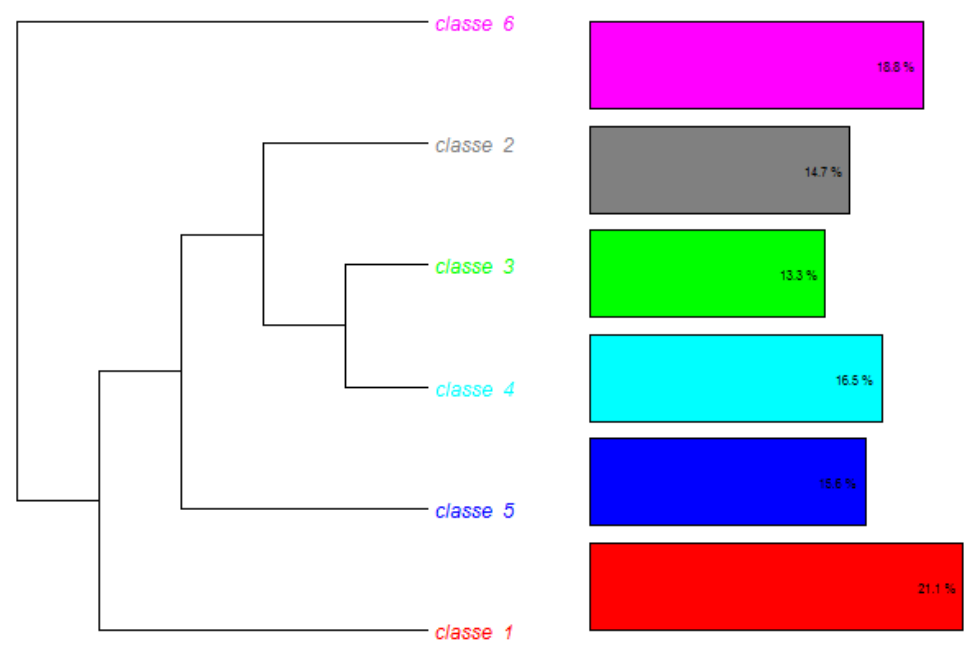

Figura 2. Dendograma de classes para o Corpus Trabalho noturno na categoria profissional saúde 
Cada classe resultante da CHD é composta pelas palavras mais significativas (maior frequência dentro da classe) e pelas respectivas associações com a classe (chi-quadrado), deste modo, a Figura 3 apresenta 15 palavras que melhor caracterizam cada uma das Classes.

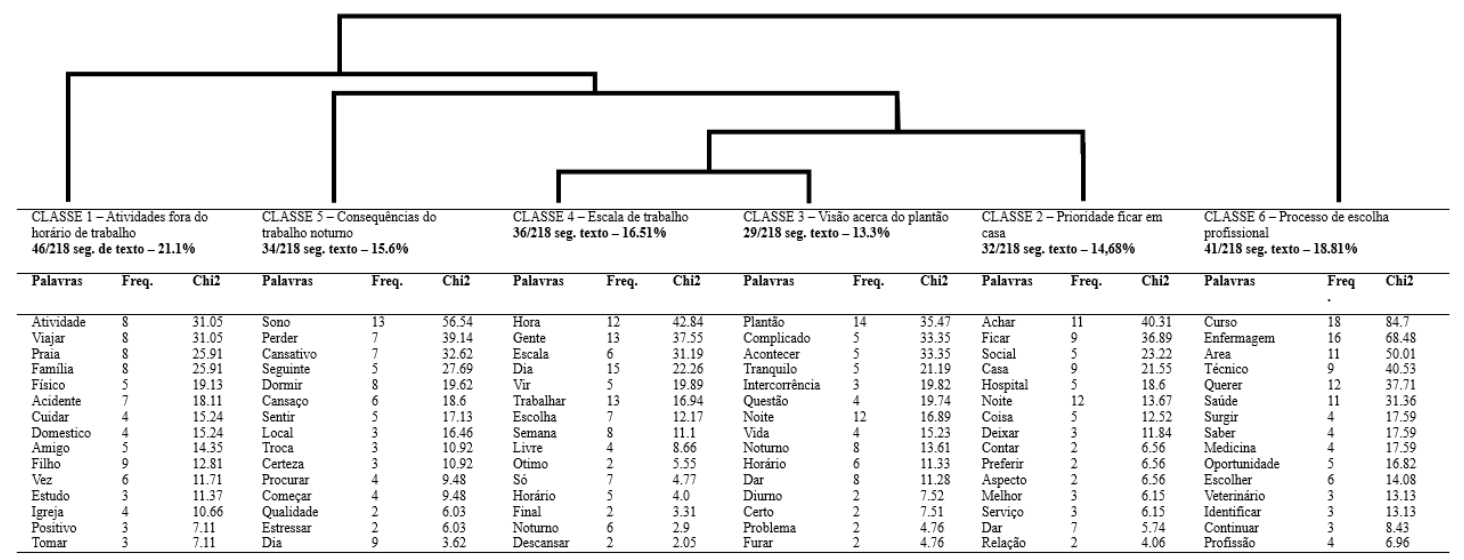

Figura 3. Dendograma de classes com verbetes mais significativos para o Corpus trabalho noturno na categoria profissional Saúde

Em função destas análises o IRAMUTEQ também seleciona os seguimentos de texto mais significativos de acordo com o $\mathrm{X}^{2}$ de cada classe. A Classe 1, denominada Atividades fora do horário de trabalho, representa $21,1 \%$ dos segmentos de texto, e as palavras que melhor se relacionam a esta classe fazem menção à atividades que os respondentes fazem quando não estão em expediente de trabalho.

Tabela 1. Segmentos de texto mais representativos da Classe 1

\begin{tabular}{cl}
\hline $\mathbf{X}^{\mathbf{2}}$ & \multicolumn{1}{c}{ Segmento de texto } \\
\hline 54.74 & $\begin{array}{l}\text { Estudos, participação ativa na família, reuniões religiosas 1 vez por semana, } \\
\text { atividades físicas e eu queria ir mais à igreja }\end{array}$ \\
\hline 31.05 & $\begin{array}{l}\text { viajar e fazer atividades físicas, já acidentes biológicos com materiais } \\
\text { perfurocortantes para mim não é compensatório não }\end{array}$ \\
\hline 31.05 & $\begin{array}{l}\text { Frequento piscinas praia, vou à igreja e viajo quase toda semana para a casa da } \\
\text { família no município vizinho }\end{array}$ \\
\hline 25.91 & $\begin{array}{l}\text { Tenho minhas atividades em casa filhos academia animais banco e rotina mesmo } \\
\text { do dia a dia da família }\end{array}$ \\
\hline 25.91 & $\begin{array}{l}\text { Eu devia fazer atividade física zumba eu amo zumba, (...) já comigo mesmo de vez } \\
\text { em quando eu me furo }\end{array}$ \\
\hline 19.13 & Saio pra comer pizza jantar fora, atividade física né, malhação já com colega já \\
\hline Nota: & Nesta tabela estão contidos apenas os 5 segmentos de texto com os maiores $X^{2}$ \\
\hline
\end{tabular}

A Classe 5, denominada Consequências do trabalho noturno, representa 15,6\% dos segmentos de texto e as palavras que melhor se relacionam a esta classe fazem menção aos efeitos do trabalho noturno na vida dos profissionais.

Tabela 2. Segmentos de texto mais representativos da Classe 5

\begin{tabular}{cl}
\hline $\mathbf{X}^{\mathbf{2}}$ & \multicolumn{1}{c}{ Segmento de texto } \\
\hline 56.54 & o daqui além de você perder o sono é cansativo \\
\hline 39.14 & $\begin{array}{l}\text { então perde muita coisa e antes de vir trabalhar você tem que dormir, eu não vou } \\
\text { em festa porque tenho muito sono }\end{array}$ \\
\hline 32.62 & $\begin{array}{l}\text { qualidade e quantidade do sono cansaço e pouca produtividade, no dia seguinte } \\
\text { vou à casa da minha mãe }\end{array}$ \\
\hline 27.69 & acarreta um cansaço mental maior devido ao sono (...) pretendo continuar porque é \\
\hline
\end{tabular}

Persp. online: hum. \& sociais aplicada., Campos dos Goytacazes, 21 (8), 37-50, 2018 
mais cansativo mas o intervalo entre um plantão e outro é maior

19.62 ele se furou com um perfurocortante, agulha (. . .) dia livre sim perder a noite de sono

Nota: Nesta tabela estão contidos apenas os 5 segmentos de texto com os maiores $X^{2}$

A Classe 4, denominada Escala de trabalho, representa $16,51 \%$ dos segmentos de texto e as palavras que melhor se relacionam a esta classe falam a respeito da escolha pelo horário de trabalho.

Tabela 3. Segmentos de texto mais representativos da Classe 4

\begin{tabular}{cl}
\hline $\mathbf{X}^{\mathbf{2}}$ & \multicolumn{1}{c}{ Segmento de texto } \\
\hline 42.48 & $\begin{array}{l}\text { a pessoa quebra o ciclo biológico, a gente não tem escolha a gente tem que } \\
\text { trabalhar 24 horas até porque é 1 plantão por semana }\end{array}$ \\
\hline 37.55 & $\begin{array}{l}\text { então como eu tinha outro emprego eu sempre quis essa escala de 24 horas aí eu } \\
\text { gosto porque no outro dia eu fico livre }\end{array}$ \\
\hline 31.19 & $\begin{array}{l}\text { a gente sempre dá um jeito até porque como agora eu estou no plantão de } 24 \text { horas } \\
\text { eu estou o resto da semana livre }\end{array}$ \\
\hline 22.26 & $\begin{array}{l}\text { então são só 24 horas noturno por semana exceto alguns extras que a gente pega } \\
\text { tem um período de adaptação }\end{array}$ \\
\hline 19.98 & $\begin{array}{l}\text { a gente não tem escolha aqui fazem a escala da gente eu não tenho problema } \\
\text { nenhum de trabalhar à noite eu até gosto }\end{array}$ \\
\hline Nota: Nesta tabela estão contidos apenas os 5 segmentos de texto com os maiores $X^{2}$ \\
\hline
\end{tabular}

A Classe 3, denominada Visão acerca do plantão, representa 13,3\% dos segmentos de texto, e as palavras que melhor se relacionam a esta classe fazem menção ao plantão dos profissionais, seu valor financeiro e à dinâmica de trabalho dos profissionais.

Tabela 4. Segmentos de texto mais representativos da Classe 3

\begin{tabular}{cl}
\hline $\mathbf{X}^{\mathbf{2}}$ & \multicolumn{1}{c}{ Segmento de texto } \\
\hline 35.47 & $\begin{array}{l}\text { assim, vão acontecer algumas mudanças eu vou passar a diminuir pela noite os } \\
\text { plantões noturnos e os diurnos }\end{array}$ \\
\hline 33.35 & $\begin{array}{l}\text { não até tem à noite o plantão é mais tranquilo do que o plantão diurno é um } \\
\text { plantão mais tranquilo tem menos intercorrência }\end{array}$ \\
\hline 33.35 & $\begin{array}{l}\text { agora está ótimo porque tenho só } 2 \text { plantões mas antes era mais complicado e essas } \\
\text { atividades familiares não ocorrem muito à noite }\end{array}$ \\
\hline 21.19 & $\begin{array}{l}\text { eu gosto da profissão é mais troca de plantão porque é muita correria na vida é } \\
\text { complicado }\end{array}$ \\
\hline 19.82 & $\begin{array}{l}\text { aqui acolá alguma técnica se fura comigo mesmo nunca aconteceu não rapaz só o } \\
\text { valor do plantão }\end{array}$ \\
\hline Nota: Nesta tabela estão contidos apenas os 5 segmentos de texto com os maiores $X^{2}$ \\
\hline
\end{tabular}

A Classe 2, denominada Prioridade: estar em casa, representa 14,68\% dos segmentos de texto, e as palavras que melhor se relacionam a esta classe elaboram discurso dos respondentes sobre os motivos para ficar em casa.

Tabela 5. Segmentos de texto mais representativos da Classe 2

\begin{tabular}{cl}
\hline $\mathbf{X}^{\mathbf{2}}$ & \multicolumn{1}{c}{ Segmento de texto } \\
\hline 40.31 & $\begin{array}{l}\text { A partir da necessidade do serviço social no hospital pedindo ajuda aos familiares } \\
\text { que ficam em casa para me dar apoio principalmente no cuidado com os pequenos }\end{array}$ \\
\hline 36.89 & Eu estou pagando ultimamente para justamente ficar em casa porque eu acho muito \\
\hline
\end{tabular}




\begin{tabular}{cl}
\hline $\begin{array}{l}\text { cansativo aí as vezes eu tenho que trocar para ficar mais tempo em casa porque eu } \\
\text { acho melhor }\end{array}$ \\
\hline 23.22 & $\begin{array}{l}\text { Passar o dia em casa a falta de sono regular ficar em apenas 1 dos hospitais para me } \\
\text { aposentar e trabalhar com assistência social }\end{array}$ \\
\hline 21.55 & Eu prefiro ficar em casa caminhar ir para a academia \\
\hline 18.6 & $\begin{array}{l}\text { Dificuldade enorme não houve tanta mudança quando você chega em casa você não } \\
\text { sai mais você fica deitado }\end{array}$ \\
\hline Nota: & Nesta tabela estão contidos apenas os 5 segmentos de texto com os maiores $X^{2}$ \\
\hline
\end{tabular}

A classe 6, denominada Processo de escolha profissional, representa 18,81\% dos segmentos de texto, e as palavras que melhor se relacionam a esta classe fazem menção ao processo de escolha da carreira profissional.

Tabela 6. Segmentos de texto mais representativos da Classe 6

\begin{tabular}{cl}
\hline $\mathbf{X}^{\mathbf{2}}$ & \multicolumn{1}{c}{ Segmento de texto } \\
\hline 84.7 & $\begin{array}{l}\text { não tinha o desejo de trabalhar na área de saúde mas surgiu a oportunidade de um } \\
\text { curso técnico de enfermagem e como não tinha outra opção aceitei }\end{array}$ \\
\hline 68.48 & fiz o curso técnico de enfermagem e acabei tendo apreço pela área \\
\hline 50.01 & $\begin{array}{l}\text { na verdade eu sempre gostei da área da saúde na época que eu fiz o curso que eu } \\
\text { mais me interessei foi enfermagem }\end{array}$ \\
\hline 40.53 & $\begin{array}{l}\text { eu queria um curso voltado para a área da saúde eu queria um curso mais elitizado } \\
\text { como medicina }\end{array}$ \\
\hline 35.71 & eu tive que cuidar 60 dias daí surgiu o interesse pelo curso técnico de enfermagem \\
\hline Nota: Nesta tabela estão contidos apenas os 5 segmentos de texto com os maiores $X^{2}$ \\
\hline
\end{tabular}

A pergunta disparadora acerca do trabalho noturno e o questionário sócio demográfico da presente pesquisa possibilitaram conhecer os aspectos traçados nos objetivos específicos sobre a dinâmica de trabalho dos profissionais da área da saúde na atualidade na cidade de Parnaíba-PI. Em relação aos principais impactos do trabalho noturno na saúde do trabalhador, foi possível observar, a partir dos discursos dos respondentes, aspectos que revelam a qualidade do trabalho na atualidade dessa categoria profissional.

Um aspecto que chama atenção é apontado por Mauro et al. (2004) e diz respeito ao aumento da sonolência e em virtude disso a queda de rendimento de algumas funções cognitivas. Silva et al. (2011) apontam para consequências da realização do trabalho no período noturno na saúde do trabalhador manifestam-se como alterações do equilíbrio biológico, dos hábitos alimentares e do sono, na perda de atenção, na acumulação de erros, no estado de ânimo e na vida familiar e social.

Benites et al. (2013) faz um complemento acerca dos prejuízos acarretados pelo trabalho que vai de encontro ao ritmo natural do funcionamento orgânico, pontuando que para além dos danos visíveis, como é o caso dos erros e acidente de trabalho, outros desequilíbrios não são facilmente verificáveis por conta de sua inespecificidade, neste segmento pode-se exemplificar os transtornos psicológicos. $\mathrm{O}$ autor abre espaço ainda para se pensar a função que o trabalho tem assumido na vida do homem, uma vez que os vínculos empregatícios têm sido precarizados. A fim de embasar seu pensamento, corrobora com Filho (2002) ao afirmar que, os efeitos do trabalho que deveriam atuar como fator de equilíbrio, desenvolvimento humano e realização pessoal, por muitas vezes, acabam sendo responsáveis pelo desequilíbrio e sofrimento dos indivíduos.

As considerações dos referidos autores podem ser exemplificadas na discussão que se segue acerca dos resultados encontrados. Assim, observa-se na Classe 5, intitulada Consequências do trabalho noturno, que a alteração do ciclo circadiano influencia nos aspectos relativos ao sono contribuindo para o cansaço mental dos profissionais conforme expressa um dos entrevistados quando afirma "tem, é o da dormida sem

Persp. online: hum. \& sociais aplicada., Campos dos Goytacazes, 21 (8), 37-50, 2018

seer.perspectivasonline.com.br 
dúvida, esse é o mais nefasto esse periodo de sono é muito danoso", "a falta da qualidade do sono compromete os meus três dias seguintes porque é tenso mesmo tendo uma perspectiva legal, o ambiente não favorece".

Condizem com o exposto acima, as considerações de Gaspar, Moreno e Menna-Barreto (1998) ao afirmarem que é comum as queixas relativas aos problemas de sono entre os profissionais que trabalham em regime de plantão, de forma a existir dificuldades para dormir durante o dia com episódios de sono mais curtos e não reparadores. Assim, quando perguntados sobre a qualidade do sono, a maioria dos respondentes disse ter dificuldades para dormir chegando a acordar várias vezes durante a noite. Houve relatos de que o sono não é relaxante, não conseguindo chegar na fase Rapid Eye Moviments - REM; por outro lado, algumas pessoas disseram não ter dificuldades, pois dormem a noite toda e até sonham. Segundo Alóe, Azevedo e Hassan (2005) o sono normal constitui-se em face da alternância dos estágios REM (Rapid Eye Moviments) e NREM (não-REM); para Kasper et al. (2017) o sono REM tem como característica um eletroencefalograma (EEG) de baixa amplitude e frequência mista. Existe uma alternância entre os sonos NREM e REM em períodos de 90 a 110 minutos de forma a compreender o ciclo de sono "ultradiano". Cabe ressaltar que em jovens adultos saudáveis, o sono REM representa 20 a $25 \%$ do sono total, e os estágios NREM N1 e N2 perfazem 50 a $60 \%$. A privação de sono degrada o desempenho cognitivo particularmente em testes que exigem vigilância continua.

Observou-se que um número significativo de profissionais mantem mais de um vínculo empregatício, fator que compromete a recuperação das horas de sono não dormidas nas noites de trabalho, como pode ser observado nos seguintes segmentos de texto "de noite é feito para você dormir e é um sono que você não recupera e às vezes eu amanheço com dor de cabeça porque eu tenho que ir para outro local de trabalho"; "há perda do sono com certeza porque no outro dia você acorda estressada mesmo com o descanso e tem gente que sai de um local de trabalho e vai para o outro".

Outro aspecto fundamental que surgiu nos resultados consistiu na prioridade, elaborada por parte dos entrevistados, em ficar mais tempo em casa para descansar e aproveitar o convívio com a família, como foi expressado por alguns entrevistados: "eu prefiro ficar em casa caminhar ir para uma academia"; "quando eu não estou trabalhando eu estou deitada em casa ou eu fico descansando". Rotemberg et al. (2001) apontam que as pessoas que trabalham à noite vivenciam um cotidiano diferente daquele vivenciado pela comunidade em geral no que concerne as alterações nos ritmos biológicos e sociais - "eu estou pagando ultimamente para justamente ficar em casa porque eu acho muito cansativo aí às vezes eu tenho que trocar para ficar mais tempo em casa porque eu acho melhor". Prata e Silva (2013) apontam que ocorrem dificuldades no convívio social e no âmbito familiar, apesar de permanecer mais tempo com os filhos, fator que pode melhorar a supervisão educacional das crianças, entretanto, compromete o tempo de repouso em decorrência destes tentarem maximizar o tempo de interação com os filhos - "dificuldade enorme não, não houve tanta mudança, quando você chega em casa você não sai mais, você fica deitado".

Foram perceptíveis nos discursos dos respondentes atividades de lazer fora do horário de trabalho com amigos "adoro cozinhar tomar café com as amigas passear com minha filha se eu tivesse mais tempo eu cuidaria mais da minha saúde", por outro lado no discurso de alguns respondentes percebeu-se uma redução das relações sociais mantidas com os amigos "eu adoro ir para a praia às vezes tomar sorvete, raramente encontro com os amigos".

Com relação à escolha do horário de trabalho, a escolha para trabalhar à noite, na maioria dos casos, não foi por parte do colaborador e sim da organização a partir do momento em que elabora a escala de trabalho "se eu pudesse escolher eu não dava plantão noturno não, dorme mal, tem o problema de no outro dia você estar cansado", "a gente não tem escolha aqui, fazem a escala da gente eu não tenho problema nenhum de trabalhar à noite eu até gosto". Percebeu-se uma relação direta dos impactos do trabalho noturno com os efeitos dele na saúde dos profissionais de modo que se torna evidente o cansaço no dia seguinte ao plantão e o desgaste mental que se agrava em grande parte dos casos devido ao cumprimento de uma dupla jornada de trabalho adjunto dos afazeres domésticos e cuidado com os filhos, no caso das mulheres, que de certa forma representa a maioria das pessoas entrevistadas nesta pesquisa. Tais resultados condizem com o que aponta Rotemberg et al. (2001) quando afirmam que diversos aspectos interferem na qualidade e 
quantidade do sono, principalmente quando se trata das atividades do cotidiano no que concerne a divisão de trabalhos domésticos e responsabilidades familiares: realidade que se apresenta como um divisor de águas entre homens e mulheres.

Outros efeitos fisiológicos apresentados por parte dos respondentes foram labirintite, aumento do peso, estresse, fraqueza no corpo e dores na coluna: dados que corroboram com o estudo realizado por Prata e Silva (2013) que aponta os efeitos do trabalho na saúde dos profissionais. Acrescenta-se ainda, de acordo com os autores, as alterações no humor, gastrite e diminuição do desempenho. Ademais a isto, no presente estudo, mais da metade dos entrevistados afirmou que faz uso de medicamentos para dor de cabeça, enxaqueca, dor nas costas e relaxamento muscular.

\section{CONCLUSÕES}

A presente pesquisa teve relevância por apresentar a dinâmica de trabalho na atualidade dos profissionais da área da saúde e desta forma fornecer subsídios para propostas de intervenção com base nas evidências encontradas.

No geral observou-se que as alterações no ciclo sono vigília influenciam no bem-estar dos trabalhadores, na medida em que afeta desde os processos fisiológicos básicos até os relacionamentos sociais mantidos com os familiares e amigos, trazendo repercussões diretas para a saúde geral. Isso pode ser percebido pelo número significativo de profissionais que possuem mais de um vínculo empregatício, fator que contribui para que tenha menos horas de descanso. O convívio familiar também deve ser considerado, e deste modo, observou-se nos resultados a prioridade em passar mais tempo com a família em detrimento de outras atividades, como sair com os amigos.

O corpo responde a essa troca de rotina cotidiana por meio do cansaço físico e mental, ademais ao estresse, sensação de fraqueza no corpo, aumento do peso e dores na coluna. Nestes termos, apesar de alguns dos participantes da pesquisa considerar que trabalhar à noite é melhor do que no horário diurno, outros verbalizaram o desejo de trocar o horário de trabalho, que na maioria das vezes não é de livre escolha do profissional, sendo imposto por parte das escalas preestabelecidas de trabalho na organização.

\section{REFERÊNCIAS}

ALBORNOZ, S. O que é trabalho. Ed. Brasiliense. São Paulo: 2008.

ALÓE, F.; AZEVEDO, A. P.; HASAN, R. Mecanismos do ciclo sono-vigília. Revista Brasileira de Psiquiatria, v. 27, supl. 1, 2005.

BERTOLAZI, A. N.; BARRETO, S. S. M. Tradução, adaptação cultural e validação de dois instrumentos de avaliação do sono de Pittsburgh: escala de sonolência de Epworth e Índice de Qualidade (Dissertação). Universidade Federal do Rio Grande do Sul, 2008.

BENITES, A. C; CAMARGO, I. S; GOULART, J. E.; CAMARGO, M. L. Relação entre transtorno do ciclo vigília-sono e trabalho noturno: desafios à segurança e saúde do trabalhador. R. Laborativa, v. 2, n. 2, 2013.

BRASIL. Presidência da República. Decreto-Lei no ${ }^{\mathbf{0}}$ 5.452, de $\mathbf{1}^{\mathbf{0}}$ de maio de 1943. Brasília, 2017. Disponível em: http://www.planalto.gov.br/ccivil_03/decreto-lei/Del5452.htm.

CAMARGO, B. V.; JUSTO, A. M. IRAMUTEQ: um software gratuito para análisede dados textuais. Temas em Psicologia, v. 21, n. 2, p. 513-518, 2013.

CAMARGO, D. A.; NEVES, S. N. H. Transtornos mentais, saúde mental e trabalho. In. GUIMARÃES, L. A. M.; GRUBITS, S. Série saúde mental e trabalho, São Paulo: Casa do psicólogo, 2004.

CAMPOS, J. M.; BELO, R. P. Trabalho noturno: características de sua dinâmica laboral e suas implicações na vida do trabalhador, (Trabalho de conclusão de curso). Universidade Federal do Piauí, 2014.

Persp. online: hum. \& sociais aplicada., Campos dos Goytacazes, 21 (8), 37-50, 2018

seer.perspectivasonline.com.br 
CODO, W. Um diagnóstico do trabalho com ênfase em saúde mental. In JACQUES, M. G.; CODO, W. Saúde mental \& trabalho: leituras. Petrópolis: Vozes, 2002.

CODO, W.; SORATTO, L.; VASQUES-MENEZES, I. Saúde mental e trabalho. In. ZANELLI, J. C.; BORGES-ANDRADE, J. E.; BASTOS, A. V. B. Psicologia, Organizações e Trabalho no Brasil, Porto Alegre: Artmed, 2014.

DROUT, X.; QUENTIN, S. Sleep Neurobiology and Critical Care Illness. Critical Care Clinics, v. 31, n. 3, 2015.

GASPAR, S.; MORENO, C.; MENNA-BARRETO, L. Os plantões médicos, o sono e a ritmicidade biológica. Revista da Associação de Medicina Brassileira, v.44, n.3, 1998.

GIL, A. C. Métodos e técnicas de pesquisa social. São Paulo: Atlas, 2008.

GOMES, M. M.; QUIHONES, M. S.; ENGELHARDT, E. Neurofisiologia do sono e aspectos farmacoterapêuticos dos seus transtornos. Revista Brasileira de Neurologia, v. 46, n. 1, 2010.

JESUS, C. S. et al. Implicações do serviço noturno nos profissionais de enfermagem hospitalar: uma revisão integrativa. Revista Uniabreu, v. 9, n. 22, 2016b.

JESUS, C. S. et al. Reflexo do serviço noturno frente às condições de trabalho, saúde, vida social e familiar do profissional de enfermagem. Criciúma: Revista Inova Saúde, v. 5, n. 2, dez $2016 \mathrm{a}$.

KASPER, D. L. et al. Medicina interna de Harrison. 19. ed. Porto Alegre: AMGH, 2017.

LISBOA, M. T. L. et al. O trabalho noturno e suas repercussões na saúde do trabalhador de enfermagem. Rio de Janeiro: Revista de Enfermagem, UERJ, v. 18, n. 3, 2010.

MARCHAND, P.; RATINAUD, P. L'analyse de similitude appliquée aux corpus textuels: les primaires socialistes pour l'élection présidentielle française (septembre-octobre 2011). Actes des 11eme Journées internationales d'Analyse statistique des Données Textuelles. JADT, p. 687-699, 2012.

MAURO, M. Y. C.; et al. Riscos ocupacionais em saúde. Revista de Enfermagem da UERJ, 2004.

MORENO, C. R. C.; FISHER, F. M.; ROTENBERG, L. A saúde do trabalhador na sociedade 24 horas. São Paulo em Perspectiva, n. 17, v. 1, 2003.

MORENO, C. R. C.; FISHER, F. M.; ROTENBERG, L. A saúde do trabalhador na sociedade 24 horas. São Paulo em Perspectiva, n. 17, v. 1, 2003.

NEVES, M. J. A. O.; et al. Influência do trabalho noturno na qualidade de vida do enfermeiro. Revista de Enfermagem da UERJ, Rio de Janeiro, v. 18, n. 1, 2010.

OMS. Constituição da organização Mundial da Saúde de 1948. São Paulo: Biblioteca virtual de Direitos Humanos, 2017.

OMS. Constituição da organização Mundial da Saúde de 1948. São Paulo: Biblioteca virtual de Direitos Humanos, 2017.

PRATA, J.; SILVA, I. S. dimensões do contexto social e organizacional: um estudo na indústria eletrônica. Revista de Psicologia Organizacional e do Trabalho v. 13, n. 2, maio-ago, 2013.

RÉGIS FILHO, G. I. Síndrome da má-adaptação ao trabalho em turnos - uma abordagem ergonômica. Revista produção, v. 11, n. 2, abril 2002.

RÉGIS FILHO, G. I. Síndrome da má-adaptação ao trabalho em turnos - uma abordagem ergonômica. Revista produção, v. 11, n. 2, abril 2002.

ROTENBERG, L.; et al. Gênero e trabalho noturno: sono, cotidiano e vivências de quem troca a noite pelo dia. Caderno de Saúde Pública. Rio de Janeiro, v. 17, n. 3, maio-jun, 2001.

SANTOS, A. A.; COSTA, O. R. S. Qualidade de vida no trabalho dos profissionais de Enfermagem que atuam no período noturno em um Hospital Escola do Sul de Minas Gerais. Revista Ciências em Saúde, v. 6, n. 1,2016.

SILVA, E. C. G. et al. Impactos gerados pelo trabalho em turnos. Perspectivas Online, v. 4, n. 13, 2010.

Persp. online: hum. \& sociais aplicada., Campos dos Goytacazes, 21 (8), 37-50, 2018

seer.perspectivasonline.com.br 
SILVA, I. S.; PRATA, J.; FERREIRA, A. I. Horários de trabalho por turnos: da avaliação dos efeitos às possibilidades de intervenção. International Journal on Working Conditions, n. 7, jun 2014.

SIMPLÍCIO, I. O. B. et al. Fatores que interferem na qualidade de vida em profissionais de enfermagem. Revista de Publicação Acadêmica da Pós-Graduação do IESPES, v. 1, n. 23, 2015. 